\title{
Factors Associated with Drain Output in Patients Undergoing to Parotidectomy
}

\author{
Haissan Iftikhar ${ }^{1}$ Rahim Dhanani ${ }^{1}$ Sohail Awan ${ }^{2}$ Nida Zahid ${ }^{1}$ Sehrish Nizar Ali Momin ${ }^{1}$ \\ ${ }^{1}$ Department of Surgery, Aga Khan University Hospital, Karachi, \\ Sindh, Pakistan \\ 2 Department of Otorhinolaryngology, Aga Khan University, \\ Karachi, Pakistan \\ Address for correspondence Haissan Iftikhar, MBBS, FCPS, MSc, \\ Department of Surgery, Aga Khan University Hospital, Main Stadium \\ Road Karachi, Karachi, Sindh, 74800, Pakistan \\ (e-mail: haissaniftikhar@gmail.com).
}

Int Arch Otorhinolaryngol 2020;24:e211-e214.

\begin{abstract}
Introduction Tumors of the parotid gland are heterogeneous. The purpose of the drain placement is to evacuate fluid that has a potential to accumulate in the dead space and cause infection after parotidectomy.

Objectives To evaluate the factors associated with drain output among patients submitted to parotidectomy.

Methods A retrospective cohort study was conducted in the Department of Otolaryngology/Head and Neck Surgery at the Aga Khan University Hospital, Karachi, from January 1994 to December 2014. Patients who underwent parotidectomy were included in the study. Linear regression analysis was used to determine the factors associated with drain output.

Results A total of 193 patients were included in the study. The mean age of the patients was 46.3 years, and $57 \%$ of them were male. Length of surgery ( $\beta$ coefficient $=24.2$; $95 \%$ confidence interval $[95 \% \mathrm{Cl}]$ : 4.94-85.26), type of neck dissection (modified radical neck dissection: $\beta=93.9$; $95 \% \mathrm{Cl}$ : $30.47-157.38$; selective neck

\section{Keywords}

- salivary glands

- neoplasms

- neck

- infection

- general surgery dissection: $\beta=79.9 ; 95 \% \mathrm{Cl}$ : $29.04-126.85$ ), and type of parotidectomy (total $\beta=45.1$; $95 \% \mathrm{Cl}: 4.94-85.26$ ) were factors that significantly influenced drain output in patients submitted to parotidectomy with or without neck dissection.

Conclusion Neck dissection, total parotidectomy and length of surgery were predictors of postoperative neck drainage in our cohort. These factors can help predict postoperative neck drain output and help in patient counselling.
\end{abstract}

\section{Introduction}

Parotidectomy is the surgical removal of the parotid gland. This surgical procedure is employed for benign and malignant lesions. ${ }^{1}$ Removal of the parotid gland as a whole or in part creates a dead space which has a potential to collect serous fluid and saliva from the dissected tissue or the remaining parotid gland itself. ${ }^{1,2}$ This fluid has a potential to cause complications such as seroma formation or a sialocele. ${ }^{1}$ To evacuate this fluid, drains are placed in the neck. Drains prevent these complications but also have the tendency to cause infection and, therefore, prolong the

received

June 28, 2019

accepted

September 7, 2019 hospital stay. ${ }^{3}$ Although the patients can be discharged with the drain, they require nursing care and, therefore, prefer to stay in the hospital until the drains are removed. ${ }^{4}$

With increasing health care costs, there has been a trend toward shorter hospital stay and day care procedures. The drains are kept until there is less than $25 \mathrm{ml}$ of fluid gain in 24 hours. Even though the drain is placed after parotid surgery, there is a deficiency of data on the factors associated with drain output in patients submitted to parotid surgery. ${ }^{1,5,6}$ The identification of the factors associated with drain output may lead to an improvement in patient

Copyright $\odot 2020$ by Thieme Revinter Publicações Ltda, Rio de Janeiro, Brazil

\section{License terms}

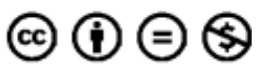


e212 Factors Associated with Drain Output in Patients Submitted to Parotidectomy Iftikhar et al.

counseling, planning of hospital stay, and selection of cases for day care procedures.

The objective of the present study was to determine the factors associated with neck drain output among patients submitted to parotidectomy.

\section{Materials and Methods}

A cross-sectional study was conducted at the Department of Otolaryngology/Head and Neck Surgery at a tertiary care hospital, from January 1994 to December 2014. The study began after receiving the approval of the ethical review committee (3619-Sur-ERC-15). We included all patients aged $\geq 18$ years with either benign or malignant lesions of the parotid, who had undergone parotid surgery with or without neck dissection. However, patients with previous surgery or radiotherapy or who had undergone treatment outside our hospital were excluded from the study. A total of 224 cases were screened, and, out of these, 193 fulfilled the eligibility criteria.

After receiving ethical approval from the institutional review board, data was collected from patient medical records on mean drain output (the outcome of the present study), the demographic characteristics of the patients, and co-morbid and clinical factors.

Drain output was measured in milliliters ( $\mathrm{ml}$ ). The Redivac drain (constant vacuum drain, Premed, Germany) was used in all of our patients. The neck drain was removed once the drain output gain in 24 hours was $\leq 30 \mathrm{ml}$.

The data was analyzed using the STATA (STATA Corp., College Station, TX, US) software, version 12. The descriptive statistics for the quantitative variables was reported by mean and standard deviation(SD), and the categorical variables were reported as frequencies and percentages. Unadjusted and adjusted $\beta$ coefficients along with their 95\% confidence intervals (95\%CIs) were reported by using simple and multiple linear regressions to assess the relationship of various factors with the mean drain output. The univariate analysis was performed for th independent variables $(p<0.25)$. Multiple linear regression was conducted for the final model $(p<0.05)$.

\section{Results}

A total of 193 parotidectomies were preformed from January 1994 to December 2014. The mean age of the patients was 46.3 years (SD: \pm 15.71 ). There were $57 \%$ of males in the sample. Diabetes mellitus type- 2 was observed in $19.1 \%$, and hypertension, in $30.7 \%$ of our patients. Regarding the type of parotidectomy, most patients (81.8\%) underwent superficial parotidectomy. Of the $16.8 \%$ who underwent neck dissection, the majority underwent selective neck dissection (9.84\%) followed by modified radical neck dissection (4.14\%), radical neck dissection (1.55\%), and superselective neck dissection (1.35\%). - Table 1

On the final histopathology, $66.44 \%$ of the cases were of benign tumors (pleomorphic adenoma: 58.09\%; Warthin tumor: $8.8 \%$ ), $17.61 \%$ were malignant tumors (mucoepidermoid: $7.77 \%$; acinic cell: $4.66 \%$; adenoid cystic: $5.18 \%$ ) and $21.7 \%$ were cases of other types of tumors (-Table 2 ). On the
Table 1 Description of patient demographic characteristics, and comorbid and tumor-related factors

\begin{tabular}{|c|c|c|}
\hline $\begin{array}{l}\text { Demographic } \\
\text { variables }\end{array}$ & & n (\%) \\
\hline $\begin{array}{l}\text { Age, years } \\
\text { (mean } \pm \text { standard } \\
\text { deviation) }\end{array}$ & & $46.3 \pm 15.7$ \\
\hline \multirow[t]{2}{*}{ Gender } & Male & $110(56.9)$ \\
\hline & Female & $83(43.01)$ \\
\hline \multicolumn{3}{|l|}{ Comorbid factors } \\
\hline \multirow[t]{2}{*}{ Diabetes mellitus } & Yes & $37(19.17)$ \\
\hline & No & $156(80.82)$ \\
\hline \multicolumn{3}{|c|}{ Surgery- and tumor-related factors } \\
\hline $\begin{array}{l}\text { Length of surgery } \\
\text { (mean } \pm \text { standard } \\
\text { deviation) }\end{array}$ & Hours & $2.76(1.13)$ \\
\hline \multirow{2}{*}{$\begin{array}{l}\text { Type of } \\
\text { parotidectomy }\end{array}$} & Superficial & $158(81.86)$ \\
\hline & Total & $35(18.13)$ \\
\hline & & n (\%) \\
\hline \multirow{5}{*}{$\begin{array}{l}\text { Type of neck } \\
\text { dissection }\end{array}$} & None & $161(83.41)$ \\
\hline & Radical & $3(1.55)$ \\
\hline & Modified & $8(4.14)$ \\
\hline & Selective & $19(9.84)$ \\
\hline & Superselective & $2(1.04)$ \\
\hline \multirow[t]{6}{*}{ Final histopathology } & $\begin{array}{l}\text { Pleomorphic } \\
\text { adenoma }\end{array}$ & $100(51.81)$ \\
\hline & Warthin & $17(8.80)$ \\
\hline & Mucoepidermoid & $15(7.77)$ \\
\hline & Acinic cell & $9(4.66)$ \\
\hline & Adenoid cystic & $10(5.18)$ \\
\hline & Other & $42(21.76)$ \\
\hline \multirow[t]{4}{*}{ Size of tumor, cm } & $0-2$ & $9(4.66)$ \\
\hline & $2-4$ & $61(31.60)$ \\
\hline & $4-6$ & $90(46.63)$ \\
\hline & $>6$ & $33(17.09)$ \\
\hline
\end{tabular}

final histopathology, most patients had tumor sizes ranging from $4 \mathrm{~cm}$ to $6 \mathrm{~cm}$.

In our final model (multivariable analysis) type of neck dissection, type of parotidectomy, and length of surgery were significant. We observed with every modified radical and selective neck dissection that there was a gain of 93.9 and 77.9 units in drain output respectively. In patients submitted to total parotidectomy, the gain was of 45.1 units, and with every 1 hour increase in length of the surgery, the drain output increased by 24.2 units. (- Tables 3 and 4)

\section{Discussion}

The parotid gland is the largest of the three major salivary glands, and the other two are the submandibular and 
Table 2 Other tumors reported on histopathology

\begin{tabular}{|l|l|l|}
\hline Tumor & Numbers & Percentage \\
\hline Reactive intraparotid node & 11 & $5.6 \%$ \\
\hline $\begin{array}{l}\text { Spindle cell lesion/ } \\
\text { Myoepithelioma }\end{array}$ & 3 & $1.55 \%$ \\
\hline Chronic sialadenitis & 3 & $1.55 \%$ \\
\hline $\begin{array}{l}\text { Dermoid cyst/Epidermal } \\
\text { inclusion cyst }\end{array}$ & 3 & $1.55 \%$ \\
\hline Lipoma & 2 & $1.3 \%$ \\
\hline Lymphoma & 2 & $1.3 \%$ \\
\hline Castleman disease & 1 & $0.5 \%$ \\
\hline Kimura disease & 1 & $0.5 \%$ \\
\hline Monomorphic adenoma & 1 & $0.5 \%$ \\
\hline Melanoma & 1 & $0.5 \%$ \\
\hline Nodular fasciitis & 1 & $0.5 \%$ \\
\hline Atypical pleomorphic adenoma & 1 & $0.5 \%$ \\
\hline
\end{tabular}

sublingual salivary glands. ${ }^{7}$ It weighs $\sim 15 \mathrm{~g}$ to $30 \mathrm{~g}$ on either side, ${ }^{7}$ and has a varied histology due to its heterogeneous cellular composition, ${ }^{8}$ and, like other organs of the body, is predisposed to benign or malignant changes that warrant an intervention. The primary modality of treatment for benign or malignant lesions of the parotid gland is still surgery. ${ }^{8}$ Surgical excision of the parotid mass leaves a dead space that can lead to serous fluid or saliva accumulation and get infected. ${ }^{1,2}$ To overcome this concern, neck drains (active or passive) are placed to evacuate this fluid.

In the literature, there is variation in the indication of neck drain removal after parotidectomy. Some authors suggest a particular cut-off volume, and others simply suggest removing the drain postoperatively, between days 2 and $7 .^{9,10}$ In the present study, the drain was removed once the 24-hour gain was lower than $30 \mathrm{ml}$. Although neck drains are placed to prevent complications and have been considered a standard of care, little has been written on the factors associated with drain output in patients undergoing parotidectomies. ${ }^{1,5}$ With increasing health care costs and a trend toward day care procedures, we analyzed the factors that could be associated with drain output that could help us stratify patients preoperatively for day care surgery. In our final model, length of surgery, type of neck dissection, final histopathology, size of tumor, age and duration of the symptoms were significantly associated with an increase in drain output.

In a study to assess the predictive factor for drain output in 69 patients submitted to superficial parotidectomy, it was observed that age was not a significant factor; ${ }^{5}$ however, in the present study, age $(p=0.001)$ was a significant factor at the univariate level, but it was insignificant on the multivariate analysis, which is in line with other studies. Diabetes mellitus was marginally significant $(p<0.058)$ in a study by Chen et al, ${ }^{1}$ but was not significant in the present study. The length of the surgery was significant in the present study $(p<0.0001)$, and this could be because the length of the surgery increases with greater dissection of parotid tissue, which could lead to more

Table 3 Univariate analysis using linear regression of individual factors affecting drain output

\begin{tabular}{|c|c|c|c|c|}
\hline Variables & & Betacoefficient & Confidence interval & $p$-value \\
\hline Age & & 1.46 & $0.59-2.31$ & 0.001 \\
\hline Gender & $\begin{array}{l}\text { Male } \\
\text { Female }\end{array}$ & $\begin{array}{l}1 \\
-28.20\end{array}$ & $\begin{array}{l}1 \\
-55.87--0.53\end{array}$ & 0.046 \\
\hline Diabetes mellitus & $\begin{array}{l}\text { No } \\
\text { Yes }\end{array}$ & $\begin{array}{l}1 \\
31.81\end{array}$ & $\begin{array}{l}1 \\
-66.68-3.05\end{array}$ & 0.073 \\
\hline Length of surgery & & 39.80 & $32.33-47.28$ & $<0.001$ \\
\hline \multirow[t]{2}{*}{ Type of parotidectomy } & Superficial & 1 & 1 & \multirow[t]{2}{*}{$<0.001$} \\
\hline & Total & 122.18 & $90.77-153.59$ & \\
\hline \multirow[t]{6}{*}{ Neck dissection } & \multicolumn{4}{|l|}{ None } \\
\hline & Radical & 1 & 1 & \multirow[t]{5}{*}{$<0.001$} \\
\hline & Modified & 70.20 & $-24.29-164.70$ & \\
\hline & Radical & 166.04 & $107.29-224.78$ & \\
\hline & Selective & 138.27 & $98.93-177.61$ & \\
\hline & Superselective & 158.54 & $43.15-273.92$ & \\
\hline \multirow[t]{2}{*}{ Histopathology } & Benign & 1 & 1 & \multirow[t]{2}{*}{$<0.001$} \\
\hline & Malignant & 88.32 & $58.37-118.26$ & \\
\hline \multirow[t]{4}{*}{ Size of tumor } & $0-2 \mathrm{~cm}$ & 1 & 1 & \multirow[t]{4}{*}{$<0.001$} \\
\hline & $2-4 \mathrm{~cm}$ & 13.24 & $-52.11-78.59$ & \\
\hline & $4-6 \mathrm{~cm}$ & 20.88 & $-43.09-84.87$ & \\
\hline & $>6 \mathrm{~cm}$ & 98.68 & $29.85-167.51$ & \\
\hline
\end{tabular}

Note: $p$-value $=0.25$ 
e214 Factors Associated with Drain Output in Patients Submitted to Parotidectomy Iftikhar et al.

Table 4 Multiple linear regression analysis for individual factors affecting postoperative drain output

\begin{tabular}{|l|l|l|l|l|}
\hline & Variables & & Beta coefficient & Confidence interval \\
\hline \multirow{2}{*}{1.} & Neck dissection & None & 1 & 1 \\
\cline { 3 - 5 } & & Radical & 15.9 & $-76.44-108.42$ \\
\cline { 3 - 5 } & & Modified radical & 93.9 & $30.47-157.38$ \\
\cline { 3 - 5 } & & Selective & 77.9 & $29.04-126.85$ \\
\cline { 3 - 5 } & & Superselective & 91.6 & $-19.74-203.04$ \\
\hline 2. & Type of parotidectomy & Superficial & 1 & 1 \\
& & Total & 45.1 & $4.94-85.26$ \\
\hline 3. & Length of surgery & Hours & 24.2 & $13.45-34.99$ \\
\hline
\end{tabular}

Note: These factors significantly predicted drain output: $F(6,186)=19.76 ; p$-value $<0.001 ; R^{2}=0.38$.

saliva leak in the postoperative period. This was not significant in the study by Chen et al, ${ }^{1}$ who also evaluated the operative time $(p<0.627)$.

The neck dissection was performed at the time of the primary resection of the parotid malignancy that was diagnosed preoperatively by fine-needle aspiration cytology (FNAC). The type of neck dissection performed for malignant parotid tumors was significant in our final model, with modified radical and selective neck dissections having a greater drain output $(p<0.001)$ when compared with radical and superselective neck dissection. Selective neck dissection leads to greater drain output because non-lymphatic structures and some fatty tissue are left behind, and they contribute to an increase in drainage when compared with radical neck dissection, in which both the lymphatic and non-lymphatic structures are removed.

In the present study, we did not find any significant differences in drain output in patients with either benign or malignant lesions $(p=0.55)$. Our results are not in line with those of another study in which malignancy was associated with more drain output. ${ }^{5}$

\section{Conclusion}

Multiple factors affect neck drain output after parotidectomies. Neck dissection, total parotidectomy and length of surgery were predictors of postoperative neck drainage in our cohort. Patients submitted to modified radical and selective neck dissection and those submitted to total parotidectomy are expected to have a high drain output. These factors can help predict postoperative neck drain output and help in patient counselling.

\section{Conflict of Interests}

The authors have none to disclose.

\section{References}

1 Chen WC, Chuang HC, Su YY, Chien CY. Predictive factors for postoperative drainage after partial superficial parotidectomy: a casecontrol study. J Laryngol Otol 2015;129(10):1020-1024

2 Witt RL. The incidence and management of siaolocele after parotidectomy. Otolaryngol Head Neck Surg 2009;140(06):871-874

3 Woods RSR, Woods JFC, Duignan ES, Timon C. Systematic review and meta-analysis of wound drains after thyroid surgery. Br J Surg 2014;101(05):446-456

4 Amir I, Morar P, Belloso A. Postoperative drainage in head and neck surgery. Ann R Coll Surg Engl 2010;92(08):651-654

5 Mofle PJ, Urquhart AC. Superficial parotidectomy and postoperative drainage. Clin Med Res 2008;6(02):68-71

6 Chua DY, Goh CHK. Drainless Parotidectomies versus Conventional Parotidectomies: Randomised Control Study on Efficacy and Safety. Ann Acad Med Singapore 2016;45(11):513-515

7 Holsinger FC, Bui DT. Anatomy, function, and evaluation of the salivary glands. Salivary gland disorders: Springer; 2007:1-16

8 Ali NS, Nawaz A, Rajput S, Ikram M. Parotidectomy: a review of 112 patients treated at a teaching hospital in Pakistan. Asian Pac J Cancer Prev 2010;11(04):1111-1113

9 Sinha UK, Ng M. Surgery of the salivary glands. Otolaryngol Clin North Am 1999;32(05):887-906

10 Souba WW, Fink MP, Jurkovic GJ. ACS surgery: principles and practice. Decker Intellectual Properties Incorporated; 2007 